\title{
Erratum to: Accelerating Single Iteration Performance of CUDA-Based 3D Reaction-Diffusion Simulations
}

\author{
John K. Holmen · David L. Foster
}

Published online: 18 February 2014

(C) Springer Science+Business Media New York 2014

\section{Erratum to: Int J Parallel Prog DOI 10.1007/s10766-013-0251-z}

The publisher regrets an error in the captions of the Tables 4 and 5. The Correct Table captions are as follows:

Table 4 Simulation speeds and speedups gathered utilizing 2.5-dimensional blocking and the "Quadrant-Load" halo region loading technique.

Table 5 Simulation speeds and speedups gathered utilizing 2.5-dimensional blocking and the "Single-Load" halo region loading technique.

The online version of the original article can be found under doi:10.1007/s10766-013-0251-z.

J. K. Holmen $(\varangle) \cdot$ D. L. Foster

Electrical and Computer Engineering Department, Kettering University, Flint, MI, USA

e-mail: holm5073@kettering.edu

D. L. Foster

e-mail: dfoster@kettering.edu 